\title{
Effect of therapy-related acute myeloid leukemia on the outcome of patients with acute myeloid leukemia
}

\author{
ANA ESPÍRITO SANTO ${ }^{1,2}$, SÉRGIO CHACIM ${ }^{1}$, ISABEL FERREIRA ${ }^{1}$, LUÍS LEITE ${ }^{1}$, CLAUDIA MOREIRA ${ }^{1}$, \\ DULCINEIA PEREIRA $^{1}$, MARGARIDA DANTAS BRITO ${ }^{1}$, MARTA NUNES $^{1}$, NELSON DOMINGUES ${ }^{1}$, \\ ISABEL OLIVEIRA $^{1,}$ ILÍDIA MOREIRA ${ }^{1}$, ANGELO MARTINS ${ }^{1}$, LUÍSA VITERBO ${ }^{1}$, \\ JOSÉ MÁRIO MARIZ ${ }^{1}$ and RUI MEDEIROS ${ }^{3-7}$ \\ ${ }^{1}$ Department of Onco-Hematology, Portuguese Institute of Oncology of Porto; ${ }^{2}$ Faculty of Medicine, \\ University of Porto; ${ }^{3}$ Molecular Oncology and Viral Pathology Group Investigation Centre, Portuguese Institute of \\ Oncology of Porto; ${ }^{4}$ Abel Salazar Institute of Biomedical Sciences, University of Porto; \\ ${ }^{5}$ Department of Oncology, Portuguese Institute of Oncology; ${ }^{6}$ Biomedical Research Centre, \\ Faculty of Health Sciences of Fernando Pessoa University; ${ }^{7}$ Department of Research, \\ Portuguese League Against Cancer (Regional North Core), Porto, Portugal
}

Received January 22, 2015; Accepted October 28, 2015

DOI: $10.3892 / 01.2016 .4591$

\begin{abstract}
Therapy-related acute myeloid leukemia (t-AML) is a rare and almost always fatal late side effect of antineoplastic treatment involving chemotherapy, radiotherapy or the two combined. The present retrospective study intended to characterize t-AML patients that were diagnosed and treated in a single referral to an oncological institution in North Portugal. Over the past 10 years, 231 cases of AML were diagnosed and treated at the Portuguese Institute of Oncology of Porto, of which 38 t-AML cases were identified. Data regarding the patient demographics, primary diagnosis and treatment, age at onset of therapy-related myeloid neoplasm, latency time of the neoplasm, cytogenetic characteristics, AML therapy and outcome were collected from medical records. A previous diagnosis with solid tumors was present in 28 patients, and 10 patients possessed a history of hematological conditions, all a lymphoproliferative disorder. Breast cancer was the most frequent solid tumor identified (39.5\% of all solid tumors diagnosed). The mean latency time was 3 years. In the present study, t-AML patients were older $(\mathrm{P}<0.001)$ and more frequently carried cytogenetic abnormalities $(\mathrm{P}=0.009)$ compared with de novo AML patients. The overall survival time was observed to be significantly poorer among individuals with t-AML
\end{abstract}

Correspondence to: Dr Ana Espirito Santo, Department of Onco-Hematology, Portuguese Institute of Oncology of Porto, Piso 6 Medicina, Rua Dr. António Bernardino de Almeida, Porto, Norte 4200-072, Portugal

E-mail: ana.esanto@ipoporto.min-saude.pt

Key words: therapy-related acute myeloid leukemia, acute myeloid leukemia, cytogenetics, age
$(\mathrm{P}<0.001)$. However, in younger patients (age, $<50$ years) there was no difference between the overall survival time of patients with t-AML and those with de novo AML $(\mathrm{P}=0.983)$. Additionally, patients with promyelocytic leukemia possess a good prognosis, even when AML occurs as a secondary event $(\mathrm{P}=0.98)$. To the best of our knowledge, the present study is the first to evaluate $\mathrm{t}-\mathrm{AML}$ in Portugal and the results are consistent with the data published previously in other populations. The present study concludes that although t-AML demonstrates a poor prognosis, this is not observed among younger patients or promyelocytic leukemia patients.

\section{Introduction}

Hematopoietic tissue malignancies are a known late side effect of previous treatments in patients that have received chemotherapy or radiotherapy for a neoplastic or other non-malignant condition (1-3). In 2008, the World Health Organization (WHO) published a review for the classification of acute leukemia (4-6) that included a novel category for neoplasms that may emerge following a previous treatment. In addition to improving treatment outcomes, the evolution of treatment options over the past decade has resulted in an increased risk of secondary malignancy $(3,7)$. The treatment options include the use of numerous novel drugs as molecular targeted agents, novel and more intense protocols that use increased maintenance regimens and neoadjuvant therapies (8-10).

The diagnosis of therapy-related acute myeloid leukemia ( $\mathrm{t}$-AML) is based on the previous exposure of a patient to cytotoxic agents $(4,6)$. In addition to this causal effect, the mechanism remains obscure; however, the mechanism appears to result from the direct mutational effect induced by prior therapy in the cells. Each cytotoxic agent may damage DNA, which may lead to various cytogenetic abnormalities and contribute to various biological characteristics in 
t-AML (11-14). The time between the primary malignancy diagnosis and AML development, which is termed the latency time, varies with the treatment and cumulative dose administered, and the dose intensification of the previous cytotoxic treatment (15-18). Morphological and cytogenetic findings are also affected by previous treatments $(3,7,15,19,20)$.

There are two distinct groups in t-AML, according to the previous treatment administered, consisting of the group of patients that were treated with alkylating agents or radiotherapy, and the group that was treated with topoisomerase II inhibitors $(3,21)$. In the first group of patients, bone marrow myelodysplastic changes usually precede $\mathrm{t}-\mathrm{AML}$, which allows a longer latency period of 5-7 years $(21,22)$. Poorer cytogenetic findings are also a hallmark of the group of patients treated with alkylating agents or radiotherapy, and are the cytogenetic findings are often accompanied by a complex karyotype with loss of cytogenetic material (21-24). Patients previously treated with topoisomerase II inhibitors usually present with balanced translocations. A shorter latency period, which can be $\sim 12$ months in certain cases, exhibits a rapidly progressive leukemia (21-25). The common usage of a combination of topoisomerase II inhibitors and alkylating agents led to the disappearance of these two groups (8-10).

t-AML is a rare and frequently fatal disease $(2,19,23,26-28)$. The poor disease outcome may be explained by numerous potential factors, which include the prognosis of the primary malignancy and the toxic products of previous cytotoxic treatments that may compromise chemotherapy for AML (2,19,23,26-28). In addition to these facts, the frequent association between t-AML and poor cytogenetics appear to result in chemotherapy resistance $(21,23,29)$.

\section{Patients and methods}

Patients. In the last 10 years, 231 patients were diagnosed with acute leukemia in the Onco-Hematology Department of the Portuguese Institute of Oncology of Porto (Porto, Norte, Portugal), the oncological referral hospital in North Portugal. Of these patients, 38 were diagnosed with t-AML. The medical records of the selected patients were reviewed in the present study. Data regarding the patient demographics, primary diagnosis and treatment, age at therapy-related myeloid neoplasm (t-MN) onset, latency time, cytogenetic characteristics, AML therapy and outcome were collected. The diagnosis of t-MN was based on the WHO 2008 classification, which concerns the previous medical history of the patient and the presence of acute leukemia laboratory findings. Bone marrow consisting of $>20 \%$ myeloblasts conferred an AML diagnosis.

The ethics committee of Instituto Português de Oncologia do Porto (Porto, Portugal) approved the present study. Written informed consent was obtained from the patients for participation in the study.

Cytogenetics. G-banding was performed on bone marrow samples obtained from the patients using standard techniques (30). The cytogenetic results were presented according to the International System for Human Cytogenetic Nomenclature (31). Patients were then analyzed according to cytogenetic risk subgroups, as defined by the Southwest Oncology Group (SWOG) (32).

Statistical analyses. An analysis of the data was performed SPSS software for Windows (version 17.0; SPSS, Inc., Chicago, IL, USA). Differences in proportions were evaluated using the $\chi^{2}$ test. The probability of survival was calculated. The means and life tables were computed using the product limit estimate of Kaplan-Meier and analyzed by the Breslow (generalized Wilcoxon) test, which is a statistical test for equality of survival distributions. $\mathrm{P}<0.05$ was considered to indicate a statistically significant difference. The hazard ratio (HR) was also assessed using multivariate Cox regression analyses of the 1-, 3- and 5-year overall survival (OS) rates. Using the HR value, the probability $(\mathrm{P})$ of survival was calculated as previously described in the literature: $\mathrm{HR}=$ odds $=\mathrm{P} /(1-\mathrm{P}) ; \mathrm{P}=\mathrm{HR} /(1+\mathrm{HR})(33)$.

The survival duration was defined as the time between diagnosis and either mortality or time of the last clinical evaluation of the patient. Only patients achieving complete remission were evaluated for disease-free survival, which was defined as the time between diagnosis and relapse. The latency interval was defined as the time period between first cytotoxic therapy and t-MN diagnosis.

\section{Results}

Patients. In total, 231 adult patients with AML were identified. The median age at diagnosis was 51 years (range, 15-78) and $58 \%(n=134)$ were females. $t-A M L$ was identified in 38 patients and the remaining 193 were diagnosed with de novo AML. Patients diagnosed with de novo AML were younger compared with t-AML patients (median age, 50 vs. 56 years; $\mathrm{P}<0.000$ ). De novo AML and t-AML were more prevalent in females than in males (55.4 vs. $71.1 \%$ ), but this was not a statistically significant difference (Table I).

Cytogenetics. An abnormal karyotype is the most frequent finding in t-AML patients when compared with $\mathrm{AML}$ patients (94.7 vs. 46.6\%; $\mathrm{P}<0.000$; Table I). Although there were no significant differences between the prevalence of cytogenetic abnormalities when stratifying patients using the SWOG score, $\mathrm{t}-\mathrm{AML}$ patients were more frequently placed in the unfavorable risk score group than AML patients ( 28.9 vs. $17.3 \%$; $\mathrm{P}=0.042$ ). Between the favorable and intermediate risk groups, no differences were found (Table I).

When analyzing the cytogenetic alterations in t-AML by comparing the solid tumors and the hematological malignancy groups, there were no significant differences. The loss of cytogenetic material was more frequent among t-AML patients following hematological malignancies. Balanced translocations, including core binding factor (CBF) abnormalities, were more frequent subsequent to diagnosis with solid tumors (Table II).

Previous disease and treatment. The majority of patients with $\mathrm{t}$-AML were previously diagnosed with a solid tumor $(\mathrm{n}=28$; $74 \%)$. The most common solid tumor was breast cancer $(n=15$; $39.5 \%)$, followed by uterine cancer $(n=4 ; 10.5 \%)$ and prostate cancer $(n=2 ; 5.3 \%)$. In total, 7 cases $(18.4 \%)$ were associated with several neoplastic conditions, each unique to a single 


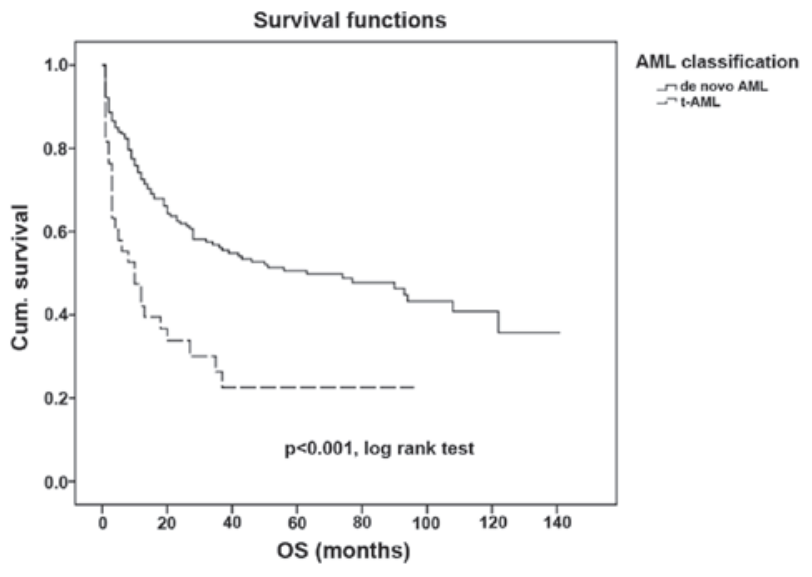

Figure 1. Overall survival time in de novo AML and in t-AML. t-AML, therapy-related acute myleoid leukemia; Cum., cumulative; OS, overall survival.

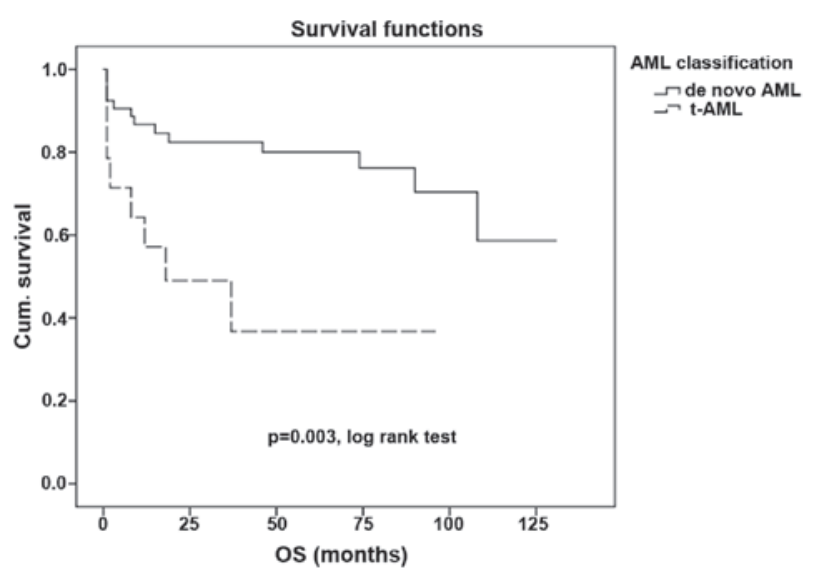

Figure 2. Overall survival time in de novo AML and in t-AML with core binding factor abnormalities. t-AML, therapy-related acute myleoid leukemia; Cum., cumulative; OS, overall survival.

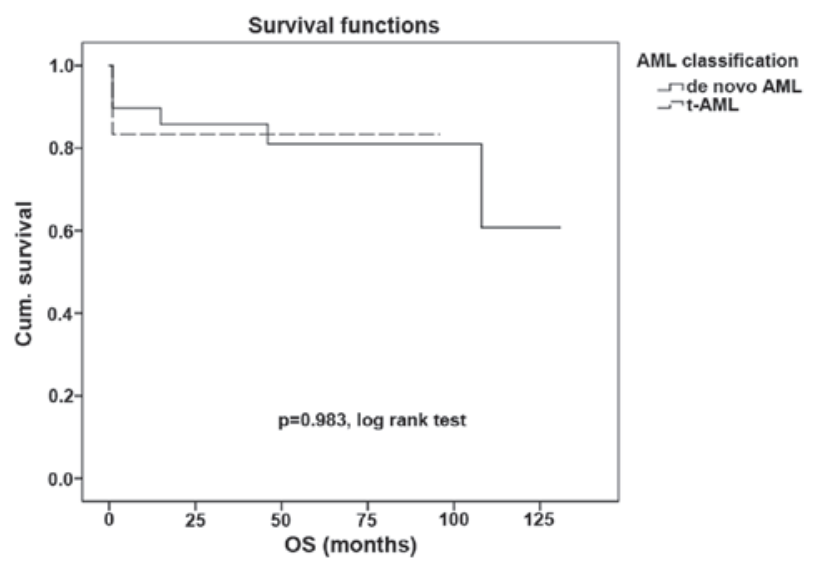

Figure 3. Overall survival time in de novo AML and in promyelocytic t-AML. t-AML, therapy-related acute myleoid leukemia; Cum., cumulative; OS, overall survival.

case. In the hematological malignancies group, a previous lymphoproliferative disorder was identified in all patients, with non-Hodgkin's lymphoma observed in 8 patients $(21.1 \%)$ and Hodgkin's lymphoma in 2 cases (5.3\%).
Chemotherapy alone was performed on 15 patients (39.5\%), 13 patients $(34.2 \%)$ were treated only with radiotherapy and the remaining patients had received previous chemo- and radiotherapy. The majority of patients treated with chemotherapy alone were treated with a combination of alkylating agents and topoisomerase II inhibitors $(n=12$; $80 \%)$. Only 3 patients (20\%) were treated with alkylating agents. The median time between the first antineoplastic treatment and t-AML was 3 years (range, 1-19 years).

According to the previous treatment received, a shorter latency time was observed in the group treated with the combination of chemo- and radiotherapy, which had a median latency time of 3.5 years (range, 2-13). However, the differences between the patients treated with chemotherapy alone, radiotherapy alone or a combination of the two lacked significance $(\mathrm{P}=0.619)$. The complete response to induction treatment was similar in de novo and therapy related $\mathrm{AML}$ groups $(\mathrm{P}=0.872)$.

Survival. The median follow-up time of all patients was 23 months (range, 1-141 months). The median OS time in the entire cohort $(n=231)$ was 39 months [95\% confidence interval (CI), 10.458-67.542] and the OS rate in the subsequent 5 years was $45.9 \%$.

The outcome of patients with t-AML is significantly poorer when compared with the outcome of patients with de novo AML $(\mathrm{P}<0.001$; Fig. 1$)$, with median OS times of 10 and 64 months, respectively. The OS rates at 5 years were 22.6 and $50.6 \%$ in patients with t-AML and de novo AML, respectively.

Cytogenetics and age are the strongest prognostic markers for the outcome in de novo AML. In the present study, cytogenetics $(\mathrm{P}=0.009 ; 95 \% \mathrm{CI}, 1.042-1.336)$ and age $(\mathrm{P}=0.008$; 95\% CI, 1.153-2.616) were of independent prognostic value in all patients. However, in the t-AML cohort, cytogenetics $(\mathrm{P}=0.392 ; 95 \% \mathrm{CI}, 0.862-1.459)$ and age $(\mathrm{P}=0.517 ; 95 \% \mathrm{CI}$, $0.539-3.423)$ lacked prognostic value.

Other core binding factor $(\mathrm{CBF})$ abnormalities that are often associated with a good prognosis often lose this association in patients with secondary leukemia ( $\mathrm{P}<0.001$; Fig. 2). However, in the $t(15,17)$ group of patients, even those with t-AML demonstrated the preservation of a good prognosis, with no statistically significant difference in survival compared with the de novo AML subgroup ( $\mathrm{P}=0.983$; Fig. 3 ).

An older age is associated with a poorer outcome in patients with t-AML. By analyzing the study population in two subgroups, one containing patients of $\leq 50$ years and another containing patients of $>50$ years, the outcome of t-AML patients in the younger subgroup was similar in $\mathrm{t}-\mathrm{AML}$ and de novo AML patients ( $\mathrm{P}=0.98$; Fig. 4). Older patients with t-AML are more likely to experience a poor prognosis when compared with their de novo counterpart ( $\mathrm{P}=0.006$; Fig. 5).

Multivariable Cox-regression analyses demonstrated a significant adverse impact on the 5-year OS rate of t-AML patients $(\mathrm{P}<0.001 ; \mathrm{HR}, 3.363$; 95\% CI, 1.951-5.796), a significant $\mathrm{HR}$ of complete response following induction treatment $(\mathrm{P}<0.001 ; \mathrm{HR}, 5.376 ; 95 \% \mathrm{CI}, 3.303-8.750)$ and a significant occurrence of relapse $(\mathrm{P}<0.001 ; \mathrm{HR}, 2.827 ; 95 \%$ CI, 1.790-4.466; Table III). 
Table I. Characteristics of patients with de novo AML and t-AML.

\begin{tabular}{|c|c|c|c|}
\hline Characteristic & De novo AML, n (\%) & $\mathrm{t}-\mathrm{AML}, \mathrm{n}(\%)$ & P-value \\
\hline Total & $193(83.5)$ & $38(16.5)$ & \\
\hline \multicolumn{4}{|l|}{ Gender } \\
\hline Male & 86 & 11 & $0.08^{\mathrm{a}}$ \\
\hline Female & 107 & 27 & \\
\hline Age, years (range) & $50(15-78)$ & $56(17-78)$ & $<0.000^{\mathrm{b}}$ \\
\hline \multicolumn{4}{|l|}{ Cytogenetics } \\
\hline Abnormal & $74(46.6)$ & $27(94.7)$ & $0.009^{\mathrm{a}}$ \\
\hline Normal & 77 (39.9) & $9(23.7)$ & \\
\hline Missing & $26(13.5)$ & $2(5.3)$ & \\
\hline $\mathrm{CBF}$ & $53(27.5)$ & $17(44.7)$ & $<0.000^{\mathrm{a}}$ \\
\hline 5,7 and 8 alterations & $13(6.7)$ & $3(7.9)$ & $0.912^{\mathrm{a}}$ \\
\hline $\mathrm{t}(9,11)$ & $8(4.1)$ & $2(5.3)$ & $0.845^{\mathrm{a}}$ \\
\hline Complex & $16(8.3)$ & $5(13.2)$ & $0.441^{\mathrm{a}}$ \\
\hline \multicolumn{4}{|l|}{ SWOG risk score } \\
\hline Favorable & $56(30.3)$ & $9(23.7)$ & $0.656^{\mathrm{a}}$ \\
\hline Intermediate & $97(52.4)$ & $14(36.8)$ & $0.228^{\mathrm{a}}$ \\
\hline Unfavorable & $32(17.3)$ & $11(28.9)$ & $0.042^{\mathrm{a}}$ \\
\hline Complete response & $150(84.3)$ & $26(68.4)$ & $0.872^{\mathrm{a}}$ \\
\hline
\end{tabular}

${ }^{\mathrm{a}} \chi^{2}$ test; ${ }^{b} \mathrm{t}$ test. AML, acute myeloid leukemia; $\mathrm{t}-\mathrm{AML}$, therapy-related acute myeloid leukemia; CBF, core-binding factor; SWOG, Southwest Oncology Group.

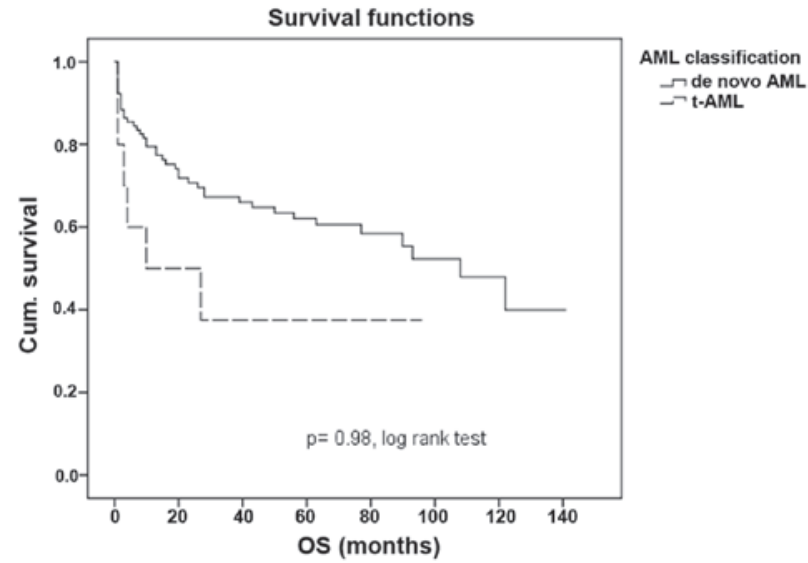

Figure 4. Overall survival time in patients younger than 50 years in de novo AML and in t-AML. t-AML, therapy-related acute myleoid leukemia; Cum., cumulative; OS, overall survival.

By independently analyzing AML and the SWOG risk score as prognostic factors, and comparing the HR for OS rate at 1, 3 and 5 years, a constant and gradual increased HR was observed for the t-AML group (Fig. 6). This trend was not observed in the same analysis for the SWOG risk, which demonstrated a decreasing HR over the years. The 5-year OS rates demonstrate a separation in the two curves, which becomes even clearer over time. The mortality risk in the t-AML group at 1 year is $75.6 \%$, and this increased to 76 and $77 \%$ at 3 and 5 years, respectively. In the SWOG group, the mortality risk decreased between $60 \%$ at 1 year and $52 \%$ at 3 and 5 years (32).

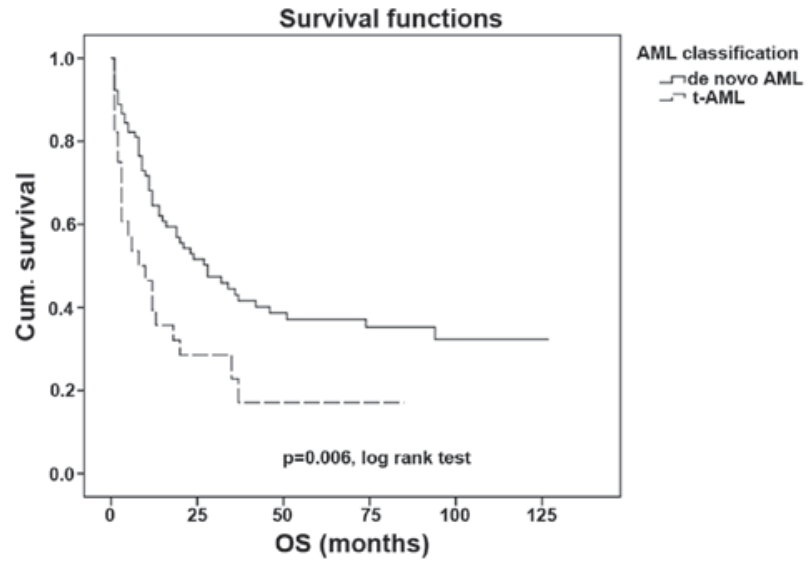

Figure 5. Overall survival time in patients older than 50 years in de novo AML and in t-AML t-AML, therapy-related acute myleoid leukemia; Cum., cumulative; OS, overall survival.

\section{Discussion}

Long-term side effects of previous cytotoxic treatments are one of the most challenging problems faced by oncologists $(2,3,7)$. The improved survival rates associated with the most efficient novel drugs allow patients to survive the primary cancer and develop a secondary malignancy induced by the cell toxicity of the primary treatment. Numerous studies have now been conducted to characterize this particular type of acute leukemia $(2,8,19,28,34)$; however, to the best of our knowledge, the present study is the first 
Table II. Cytogenetic abnormalities, according to the type of tumor.

\begin{tabular}{|c|c|c|c|}
\hline Karyotype & Solid tumor, n (\%) & Hematological malignancy, n (\%) & P-value \\
\hline Total & $28(100.0)$ & $8(80)$ & \\
\hline Normal & $6(21.4)$ & $3(30)$ & 0.355 \\
\hline $\mathrm{CBF}$ and balanced translocations & $17(60.7)$ & $2(20)$ & 0.743 \\
\hline Alterations on chromosomes 5,7 and 8 & $2(7.1)$ & $1(10)$ & 0.629 \\
\hline Complex & $3(10.7)$ & $2(20)$ & 0.303 \\
\hline
\end{tabular}

P-values were calculated using the $\chi^{2}$ test. $\mathrm{CBF}$, core-binding factor.

Table III. Multivariate analyses of 5-year overall survival.

\begin{tabular}{lrrr}
\hline & & & 5-year overall survival \\
\cline { 3 - 4 } Factors & P-value & HR & $95 \%$ CI \\
\hline t-AML & $<0.001$ & 3.363 & $1.951-5.796$ \\
Age & 0.065 & 1.523 & $0.974-2.382$ \\
Gender & 0.736 & 0.928 & $0.601-1.433$ \\
SWOG risk score & 0.864 & 1.048 & $0.614-1.787$ \\
Complete response & $<0.001$ & 5.376 & $3.303-8.750$ \\
Relapse & $<0.001$ & 2.827 & $1.790-4.466$ \\
\hline
\end{tabular}

HR indicates the risk of mortality within 5 years; HR, hazard ratio; CI, confidence interval; t-AML, therapy-related acute myeloid leukemia; SWOG, Southwest Oncology Group.

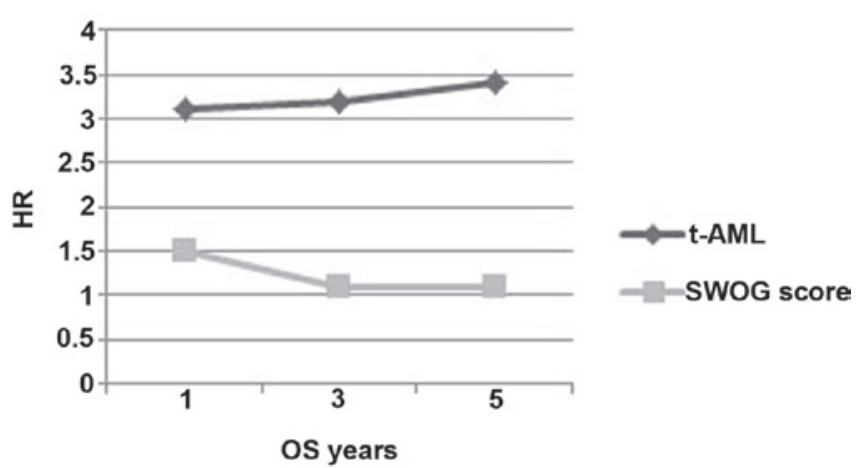

Figure 6. t-AML and SWOG score risk as independent prognostic factors: Comparing HR within the 1, 3 and 5 year timeline. t-AML, therapy-related acute myleoid leukemia; HR, hazard ratio; OS, overall survival; SWOG, Southwest Oncology Group.

to analyze therapy-induced secondary malignancy in Portuguese patients.

The frequency of $\mathrm{t}-\mathrm{AML}$ in the present cohort was $16.5 \%(8,27)$, which is increased compared with previously reported data from other populations. This may be explained by the focused activity of the present hospital, an oncology referral center, which may lead to a clustering of all oncological conditions.

The response to the induction regimen was not significantly different between patients with t-AML and those with de novo AML. This suggests that t-AML patients do not demonstrate a worse response to chemotherapy compared with de novo AML patients, and also suggests that the comparably poor outcome of patients with t-AML is likely to be a result of toxicity or relapse from acute leukemia or the initial tumor (35).

Cytogenetics acts as a good prognostic marker in patients with AML (8,23,24,27,36-38). Patients with t-AML are more prone to a poor prognosis and cytogenetic findings. Core binding factor abnormalities are associated with an improved outcome in patients with AML (39-41). However, in the present cohort, $\mathrm{t}(15,17)$ appeared to have a good effect on the outcome of disease, even in patients with t-AML (42-45).

t-AML patients are generally older than patients with de novo AML. Older age has previously been linked with a poorer prognosis (42). Comorbidities and primary resistance disease have been associated with a poorer outcome (43-45). By analyzing the present data, younger t-AML patients were concluded to behave equally to de novo AML patients of the same age. However, older t-AML patients demonstrated a significantly poorer outcome compared with de novo AML patients of the same age.

In the present study, t-AML was a solid independent prognostic marker, persisting over 5 years, and was associated with a trend of increased HR. By contrast, the SWOG risk score behaved differently, losing relevance as a prognostic marker over time. A possible explanation for this observation may be that the prognostic relevance of the SWOG risk is scored only at diagnosis and not following the onset of relapse, when other cytogenetic abnormalities may occur, de novo or in association with the initial anomaly. From the present study, 
t-AML may be concluded to be a serious late side effect of a previous oncological treatment. The incidence of t-AML may be increasing due to the use of more effective therapeutic strategies, which may lead to an increased life expectancy, therefore making it possible for late side effects to appear.

Despite the poor prognosis of t-AML, certain groups of patients may be identified that have a similar outcome to de novo AML patients (46-48). Promyelocytic leukemia continues to demonstrate a good prognosis, even when appearing as a secondary event following a previous malignancy $(49,50)$; this is perhaps due to the therapy used in this particular leukemia type, including specific target agents in addition to chemotherapy.

Improvements to the outcome of t-AML depend on a deeper understanding of the disease etiology, and also depend on the use of novel drugs with increased efficacy and limited toxicity, and a preventive strategy (27). Additional studies are required, particularly to better characterize this subset of patients. Clinical trials that use novel drugs often exclude t-AML patients by omitting secondary leukemia from novel drug approval.

\section{References}

1. Larson RA: Therapy-related myeloid neoplasms. Haematologica 94: 454-459, 2009.

2. Morton LM, Dores GM, Tucker MA, Kim CJ, Onel K, Gilbert ES, Fraumeni JF Jr and Curtis RE: Evolving risk of therapy-related acute myeloid leukemia following cancer chemotherapy among adults in the United States, 1975-2008. Blood 121: 2996-3004, 2013.

3. Leone G, Fianchi L and Voso MT: Therapy-related myeloid neoplasms. Curr Opin Oncol 23: 672-680. 2011.

4. Vardiman JW, Thiele J, Arber DA, Brunning RD, Borowitz MJ, Porwit A, Harris NL, Le Beau MM, Hellström-Lindberg E, Tefferi A and Bloomfield CD: The 2008 revision of the World Health Organization (WHO) classification of myeloid neoplasms and acute leukemia: Rationale and important changes. Blood 114: 937-951, 2009.

5. Vardiman JW, Harris NL and Brunning RD: The World Health Organization (WHO) classification of the myeloid neoplasms Blood 100: 2292-2302, 2002.

6. Vardiman JW: The World Health Organization (WHO) classification of tumors of the hematopoietic and lymphoid tissues: An overview with emphasis on the myeloid neoplasms. Chem Biol Interact 184: 16-20. 2010.

7. Leone G, Fianchi L, Pagano L and Voso MT: Incidence and susceptibility to therapy-related myeloid neoplasms. Chem Biol Int 184: 39-45, 2010

8. Kayser S, Döhner K, Krauter J, Köhne CH, Horst HA, Held G, von Lilienfeld-Toal M, Wilhelm S, Kündgen A, Götze K, et al, German-Austrian AMLSG: The impact of therapy-related acute myeloid leukemia (AML) on outcome in 2853 adult patients with newly diagnosed AML. Blood 117: 2137-2145, 2011.

9. Siegel R, Ma J, Zou Z and Jemal A: Cancer statistics, 2014. CA Cncer J Clin 64: 9-29, 2014.

10. Siegel R, DeSantis C, Virgo K, Stein K, Mariotto A, Smith T, Cooper D, Gansler T, Lerro C, Fedewa S, et al: Cancer treatment and survivorship statistics, 2012. CA Cancer J Clin 62: 220-241, 2012.

11. Wong TN, Ramsingh G, Young AL, Miller CA, Touma W, Welch JS, Lamprecht TL, Shen D, Hundal J, Fulton RS, et al: Role of TP53 mutations in the origin and evolution of therapy-related acute myeloid leukaemia. Nature 518: 552-555, 2015.

12. Li L, Li M, Sun C, Francisco L, Chakraborty S, Sabado M, McDonald T, Gyorffy J, Chang K, Wang S, et al: Altered hematopoietic cell gene expression precedes development of therapy-related myelodysplasia/acute myeloid leukemia and identifies patients at risk. Cancer cell 20: 591-605, 2011.

13. Pedersen-Bjergaard J, Andersen MK, Andersen MT and Christiansen DH: Genetics of therapy-related myelodysplasia and acute myeloid leukemia. Leukemia 22: 240-248, 2008.
14. Pedersen-Bjergaard J, Pedersen M, Roulston D and Philip P: Different genetic pathways in leukemogenesis for patients presenting with therapy-related myelodysplasia and therapy-related acute myeloid leukemia. Blood 86: 3542-3552, 1995.

15. Brusamolino E, Gotti $M$ and Fiaccadori V: The risk of therapy-related myelodysplasia/acute myeloid leukemia in Hodgkin lymphoma has substantially decreased in the ABVD era abolishing mechlorethamine and procarbazine and limiting volumes and doses of radiotherapy. Mediterr J Hematol Infect Dis 4: e2012022, 2012.

16. Brusamolino E, Baio A, Orlandi E, Arcaini L, Passamonti F, Griva V, Casagrande W, Pascutto C, Franchini P and Lazzarino M: Long-term events in adult patients with clinical stage IA- IIA nonbulky Hodgkin's lymphoma treated with four cycles of doxorubicin, bleomycin, vinblastine, and dacarbazine and adjuvant radiotherapy: A single-institution 15-year follow-up. Clin Cancer Res 12: 6487-6493, 2006.

17. Brusamolino E, Anselmo AP, Klersy C, Santoro M, Orlandi E, Pagnucco G, Lunghi F, Maurizi-Enrici R, Baroni CD, Lazzarino $\mathrm{M}$, et al: The risk of acute leukemia in patients treated for Hodgkin's disease is significantly higher aft [see bined modality programs than after chemotherapy alone and is correlated with the extent of radiotherapy and type and duration of chemotherapy: A case-control study. Haematologica 83: 812-823, 1998

18. Delwail V, Jais JP, Colonna P and Andrieu JM: Fifteen-year secondary leukaemia risk observed in 761 patients with Hodgkin's disease prospectively treated by MOPP or ABVD chemotherapy plus high-dose irradiation. Br J Haematol 118: 189-194, 2002.

19. Koontz MZ, Horning SJ, Balise R, Greenberg PL, Rosenberg SA, Hoppe RT and Advani RH: Risk of therapy-related secondary leukemia in Hodgkin lymphoma: The Stanford University experience over three generations of clinical trials. J Clin Oncol 31: 592-598, 2013.

20. Eichenauer DA and Engert A: Therapy-related myeloid neoplasms in patients treated for Hodgkin lymphoma. Mediterr J Hematol Infect Dis 3: e2011046, 2011.

21. Godley LA and Larson RA: Therapy-related myeloid leukemia. Semin Oncol 35: 418-429, 2008

22. Rund D, Krichevsky S, Bar-Cohen S, Goldschmidt N, Kedmi M, Malik E, Gural A, Shafran-Tikva S, Ben-Neriah S and Ben-Yehuda D: Therapy-related leukemia: Clinical characteristics and analysis of new molecular risk factors in 96 adult patients. Leukemia 19: 1919-1928, 2005.

23. Chen Y, Estrov Z, Pierce S, Qiao W, Borthakur G, Ravandi F, Kadia T, Brandt M, O’Brien S, Jabbour E, et al: Myeloid neoplasms after breast cancer: "Therapy-related" not an independent poor prognostic factor. Leuk Lymphoma 56: 1012-1019, 2015.

24. Larson RA: Cytogenetics, not just previous therapy, determines the course of therapy-related myeloid neoplasms. J Clin Oncol 30: 2300-2302, 2012.

25. Olney HJ, Mitelman F, Johansson B, Mrózek K, Berger R and Rowley JD: Unique balanced chromosome abnormalities in treatment-related myelodysplastic syndromes and acute myeloid leukemia: report from an international workshop. Genes Chromosomes Cancer 33: 413-423, 2002.

26. Paschka P, Du J, Schlenk RF, Gaidzik VI, Bullinger L, Corbacioglu A, Späth D, Kayser S, Schlegelberger B, Krauter $\mathrm{J}$, et al: Secondary genetic lesions in acute myeloid leukemia with inv(16) or $\mathrm{t}(16 ; 16)$ : A study of the German-Austrian AML Study Group (AMLSG). Blood 121: 170-177, 2013.

27. Churpek JE and Larson RA: The evolving challenge of therapy-related myeloid neoplasms. Best Pract Res Clin Haematol 26: 309-317, 2013

28. Huh HJ, Lee SH, Yoo KH, Sung KW, Koo HH, Kim K, Jang JH, Jung C, Kim SH and Kim HJ: Therapy-related myeloid neoplasms in 39 Korean patients: A single institution experience. Ann Lab Med 33: 97-104, 2013

29. Schoch C, Kern W, Schnittger S, Hiddemann W and Haferlach T: Karyotype is an independent prognostic parameter in therapy-related acute myeloid leukemia (t-AML): An analysis of 93 patients with t-AML in comparison to 1091 patients with de novo AML. Leukemia 18: 120-125, 2004.

30. Wang HC and Fedoroff S: Banding in human chromosomes treated with trypsin. Nat New Biol 235: 52-54, 1972.

31. Gonzalez Garcia JR and Meza-Espinoza JP: Use of the International System for Human Cytogenetic Nomenclature (ISCN). Blood 108: 3952-3953, 2006 
32. Slovak ML, Kopecky KJ, Cassileth PA, Harrington DH, Theil KS, Mohamed A, Paietta E, Willman CL, Head DR, Rowe JM, et al: Karyotypic analysis predicts outcome of preremission and postremission therapy in adult acute myeloid leukemia: A Southwest Oncology Group/Eastern Cooperative Oncology Group Study. Blood 96: 4075-4083, 2000.

33. Spruance SL, Reid JE, Grace M and Samore M: Hazard ratio in clinical trials. Antimicrob Agents Chemother 48: 2787-2792, 2004.

34. Suvajdžić N, Cvetković Z, Dorđević V, Kraguljac-Kurtović N, Stanisavljević D, Bogdanović A, Djunić I, Colović N, Vidović A, Elezović I and Tomin D: Prognostic factors for therapy-related acute myeloid leukaemia (t-AML) - a single centre experience. Biomed Pharmacother 66: 285-292, 2012.

35. Quesnel B, Kantarjian H, Bjergaard JP, Brault P, Estey E, Lai JL, Tilly H, Stoppa AM, Archimbaud E, Harousseau JL, et al: Therapy-related acute myeloid leukemia with $\mathrm{t}(8 ; 21)$, inv(16), and $\mathrm{t}(8 ; 16)$ : A report on 25 cases and review of the literature. J Clin Oncol 11: 2370-2379, 1993

36. Larson RA and Le Beau MM: Prognosis and therapy when acute promyelocytic leukemia and other "good risk" acute myeloid leukemias occur as a therapy-related myeloid neoplasm. Mediterr J Hematol Infect Dis 3: e2011032, 2011.

37. Feldman EJ: Does therapy-related AML have a poor prognosis, independent of the cytogenetic/molecular determinants? Best Pract Res Clin Haematol 24: 523-526, 2011.

38. Grimwade D, Hills RK, Moorman AV, Walker H, Chatters $\mathrm{S}$, Goldstone $\mathrm{AH}$, Wheatley K, Harrison CJ and Burnett AK ; National Cancer Research Institute Adult Leukaemia Working Group: Refinement of cytogenetic classification in acute myeloid leukemia: determination of prognostic significance of rare recurring chromosomal abnormalities among 5876 younger adult patients treated in the United Kingdom Medical Research Council trials. Blood 116: 354-365, 2010.

39. Hospital MA, Prebet T, Bertoli S, Thomas X, Tavernier E, Braun T, Pautas C, Perrot A, Lioure B, Rousselot P, et al: Core-binding factor acute myeloid leukemia in first relapse: $\mathrm{A}$ retrospective study from the French AML Intergroup. Blood 124: 1312-1319, 2014

40. Solh M, Yohe S, Weisdorf D and Ustun C: Core-binding factor acute myeloid leukemia: Heterogeneity, monitoring, and therapy. Am J Hematol 89: 1121-1131, 2014.
41. Duployez N, Willekens C, Marceau-Renaut A, Boudry-Labis E and Preudhomme C: Prognosis and monitoring of core-binding factor acute myeloid leukemia: Current and emerging factors. Expert Rev Hematol 8: 43-56, 2015.

42. Foran JM: Frontline therapy of AML: Should the older patient be treated differently? Curr Hematol Malig Rep 9: 100-108, 2014.

43. van der Holt B, Van den Heuvel-Eibrink MM, Van Schaik RHN, van der Heiden IP, Wiemer EAC, Vossebeld PJM, Löwenberg B, Sonneveld P: ABCB1 gene polymorphisms are not associated with treatment outcome in elderly acute myeloid leukemia patients. Clin Pharmacol Ther 80: 427-439, 2006.

44. Leith CP, Kopecky KJ, Chen IM, Eijdems L, Slovak ML, McConnell TS, Head DR, Weick J, Grever MR, Appelbaum FR and Willman CL: Frequency and clinical significance of the expression of the multidrug resistance proteins MDR1/P-glycoprotein, MRP1, and LRP in acute myeloid leukemia: A Southwest Oncology Group Study. Blood 94: 1086-1099, 1999.

45. Benderra Z, Faussat AM, Sayada L, Perrot JY, Tang R, Chaoui D, Morjani H, Marzac C, Marie JP and Legrand O: MRP3, BCRP, and P-glycoprotein activities are prognostic factors in adult acute myeloid leukemia. Clin Cancer Res 11: 7764-7772, 2005.

46. Appelbaum FR, Kopecky KJ, Tallman MS, Slovak ML, Gundacker HM, Kim HT, Dewald GW, Kantarjian HM, Pierce SR and Estey EH: The clinical spectrum of adult acute myeloid leukaemia associated with core binding factor translocations. Br J Haematol 135: 165-173, 2006.

47. Schlenk RF, Benner A, Krauter J, Buchner T, Sauerland C, Ehninger G, Schaich M, Mohr B, Niederwieser D, Krahl R, Pasold R, et al: Individual patient data-based meta-analysis of patients aged 16 to 60 years with core binding factor acute myeloid leukemia: A survey of the German Acute Myeloid Leukemia Intergroup. J Clin Oncol 22: 3741-3750, 2004.

48. Aldoss I and Pullarkat V: Therapy-related acute myeloid leukemia with favorable cytogenetics: still favorable? Leuk Res 36: 1547-1551, 2012.

49. Andersen MK and Pedersen-Bjergaard J: Therapy-related MDS and AML in acute promyelocytic leukemia. Blood 100: 1928-1929, 2002.

50. Beaumont M, Sanz M, Carli PM, Maloisel F, Thomas X, Detourmignies L, Guerci A, Gratecos N, Rayon C, San Miguel J, et al: Therapy-related acute promyelocytic leukemia. J Clin Oncol 21: 2123-2137, 2003 